\title{
Environmental and Regulatory Concerns During the COVID-19 Pandemic: Results from the Pandemic Food and Stigma Survey
}

\author{
Maik Kecinski $^{1}$ (D) Kent D. Messer ${ }^{1} \cdot$ Brandon R. McFadden $^{1} \cdot$ Trey Malone $^{2}$
}

Accepted: 27 June 2020 / Published online: 10 July 2020

(c) Springer Nature B.V. 2020

\begin{abstract}
In this article, we present data from the monthly Pandemic Food and Stigma Survey (PFSS), a nationwide representative sample of adults in the United States designed to identify how the pandemic is affecting concerns about food and the environment. Two surveys were conducted in May and June 2020. Our analysis suggests that the public's concern about contracting COVID-19 has been high; however, infection with COVID-19 was not the only concern. A majority of respondents remained strongly concerned about environmental issues, such as climate change, while responses to sudden relaxations of environmental and food safety policies varied. We analyze the PFSS data to identify factors associated with concerns about pandemic and environmental regulatory changes. In general, we find that people whose food security has been threatened by COVID-19 remain concerned about relaxation of environmental regulations, and those most inclined to take steps to reduce spread of the virus, such as wearing masks and social distancing, are more concerned about relaxed regulations than those less willing to take mitigating actions.
\end{abstract}

Keywords COVID-19 · Environmental attitudes $\cdot$ Environmental regulations $\cdot$ Food safety regulations

JEL Classification $\mathrm{C} 83 \cdot \mathrm{I} 12 \cdot \mathrm{I} 18 \cdot \mathrm{Q} 58$

Electronic supplementary material The online version of this article (https://doi.org/10.1007/s 1064 0-020-00438-9) contains supplementary material, which is available to authorized users.

Kent D. Messer

messer@udel.edu

1 Department of Applied Economics and Statistics, University of Delaware, 531 S. College Ave, Newark, DE 19716, USA

2 Department of Agricultural, Food, and Resource Economics, Michigan State University, 446 W Circle Dr, East Lansing, MI 48824, USA 


\section{Introduction}

The rapid spread of SARS-CoV-2, the virus that caused the COVID-19 pandemic, led to drastic government, business, and individual actions that exposed many human behaviors previously cloaked by "normalcy." Though the news media has been saturated with popular press reports and anecdotal accounts of responses to the pandemic, little (if any) data, to date, has been collected that sheds light on how the pandemic is shaping our perceptions and behaviors.

While a substantial amount of new regulations was passed to address the pandemic, many environmental policies and regulations have been relaxed or suspended since COVID-19 began to spread in the United States. On March 26, for example, the U.S. Environmental Protection Agency (EPA) issued an order called COVID-19 Implications for EPA's Enforcement and Compliance Assurance Program that was effective retroactively to March 13 (EPA 2020) that stated:

EPA does not expect to seek penalties for violations of routine compliance monitoring, integrity testing, sampling, laboratory analysis, training, and reporting or certification obligations in situations where the EPA agrees that COVID-19 was the cause of the noncompliance.

Furthermore, on March 31, the EPA reduced the year-over-year standard to decrease vehicle emissions from 5 to $1.5 \%$, a decrease of more than two-thirds. This reduction is concerning given recent evidence that poor air quality affects death rates associated with COVID-19, and even a small increase in exposure to fine particulate matter is associated with an increase in death rates (Wu et al. 2020) and increases in violent crimes (Burkhardt et al. 2019; Bondy et al. 2020). These relaxations in regulations have opened the door to additional requests from companies citing the pandemic as interfering with the ability to comply with longstanding regulations (NWRA 2020). Furthermore, the federal government has cited the stalled economy as motivation to fast-track infrastructure projects so that they cannot be slowed by environmental laws.

These cases of environmental deregulation have the potential to influence long-term outcomes since contamination and pollution often remain in the environment for decades, creating lasting negative repercussions for the health of people and animals (Greenstone and Fan 2018), cultural and Indigenous injustices (Zentner et al. 2019), and the value of properties affected by or situated near the source of the pollution (Messer et al. 2006). Most of the environmental regulations were designed to serve the interests of the public; that is, they were enacted to fulfill a critical mandate of government: addressing market failures and externalities that businesses and individuals do not adequately address on their own. To an economist, current requirements to mitigate transmission of COVID-19, such as wearing face masks in public, social distancing, and increased handwashing, are similar to environmental regulations. They require coordinated government interference in the market to produce welfare-enhancing outcomes that the markets will not achieve on their own. Thus, suspension of environmental regulations is expected to increase risks to human health while COVID-19 measures are being enacted to reduce those risks.

Concurrent with the removal of environmental regulations are the additions of some food safety regulations due to possible transmission of COVID-19 via human interaction. COVID-19 has spurred new guidance and regulations for every actor along the food system (FDA 2020). For example, in an effort to mitigate transmission at meat processing facilities, the Center for Disease Control and the U.S. Department of Labor issued changes in 
worker spacing requirements. Further down the supply chain, the way consumers purchase food also changed greatly; from gentle nudges on where to stand when paying for groceries to the reopening of dining options.

In this article, we analyze data from the Pandemic Food and Stigma Survey (PFSS), which was developed, in part, to track U.S. residents' concerns about violations of environmental policies and food safety regulations during the pandemic. Since we are only beginning to learn how the pandemic affects human beliefs and behavior, the PFSS was designed to facilitate this type of real-time exploration and analysis, providing guidance for researchers in formulating new research questions and designing studies to explore those questions, thereby supporting policymakers in their efforts to mitigate the environmental, societal, and economic impacts of the pandemic. Our main findings suggest that people who are most directly affected by the pandemic, such as those who have recently gone without food, and people who are most concerned about the transmission of the virus and contracting it are more likely than others to be concerned about violations to environmental and food safety regulations and policies.

\section{Survey Instrument}

The PFSS was developed to (1) provide critical time-sensitive information to the public, businesses, and policymakers about people's perceptions of risks posed by the pandemic and governmental responses to mitigate the risk and (2) analyze individual behavioral responses to the pandemic, mitigation efforts, and changing environmental conditions. Furthermore, the PFSS was designed to be an ongoing assessment of the potentially significant economic and environmental implications of COVID 19 based on the assumption that consumers' concerns and behaviors will evolve over time in response to new information and preventive measures. All procedures used in the PFSS received from the Institutional Review Board at the University of Delaware prior to being implemented.

Data for the PFSS were collected from two surveys distributed to U.S. residents online through Qualtrics ${ }^{\circledR}$. The two surveys were administered between May 19 to May 27 and June 2 to June 8, 2020, respectively. Both surveys had a sample size of 1050 respondents, and the demographic characteristics of these samples can be found in the "Appendix".

While this PFSS survey is not the first to explore changes in food and environmental policy perceptions (Lusk 2017), it is unique in its focus on policy-relevant changes during the COVID-19 pandemic. Questions of interest for this study focus on changes in concerns related to environmental and food safety regulations. Specifically, we asked participants, "How concerned are you that environmental practices and regulations are being violated during the COVID-19 pandemic?" and "How concerned are you that food safety regulations are being violated during the COVID-19 pandemic?" The response options were a five-point Likert scale ranging from "extremely unconcerned" to extremely concerned."

\section{Results}

In this section, we compare respondents' concerns in May and June about the health of the environment during the COVID-19 pandemic. Having data for 2 months allows for (1) comparing consumers' rankings of their greatest and least concerns about risk during the pandemic in May and June, and (2) using the combined May and June data to provide 
Table 1 Respondent concern about violations of regulations during the COVID-19 pandemic

\begin{tabular}{llllll}
\hline Level of concern & \multicolumn{2}{l}{ May } & & June & \\
\cline { 2 - 3 } \cline { 5 - 6 } & $\begin{array}{l}\text { Environmental prac- } \\
\text { tices and regulations } \\
(\%)\end{array}$ & $\begin{array}{l}\text { Food safety } \\
\text { regulations } \\
(\%)\end{array}$ & & $\begin{array}{l}\text { Environmental Prac- } \\
\text { tices and regulations } \\
(\%)\end{array}$ & $\begin{array}{l}\text { Food safety } \\
\text { regulations } \\
(\%)\end{array}$ \\
\hline Extremely unconcerned & 9.14 & 6.57 & & 8.57 & 6.67 \\
Somewhat unconcerned & 11.81 & 10.48 & & 12.95 & 11.24 \\
Neither concerned nor & 28.95 & 29.24 & 26.95 & 23.24 \\
$\quad$ unconcerned & 32.86 & 34.86 & & 29.81 & 33.62 \\
Somewhat concerned & 17.24 & 18.86 & 21.71 & 25.14 \\
Extremely concerned & & &
\end{tabular}

Going to a public park without social distancing rules in place Going to a public park with social distancing rules in place Being in close proximity to strangers Being in close proximity to friends Being in close proximity to family members Attending a gathering hosted outdoors Attending a gathering hosted indoors $-60 \%$

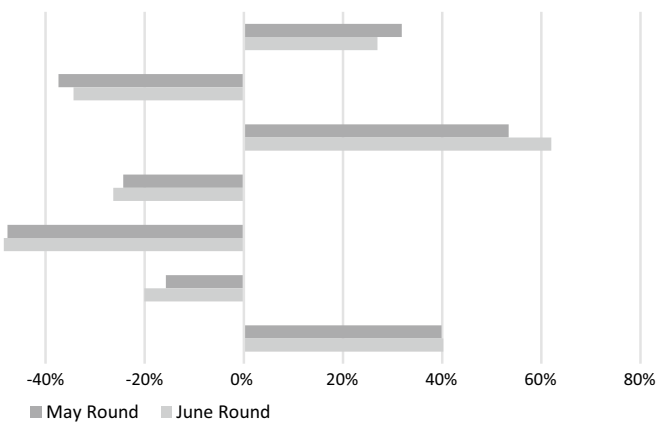

Fig. 1 Most and least stated COVID-19 related concerns between May and June 2020. Note: Bars from zero percent going left indicate least concern, whereas bars from zero going right indicate most concern

further insights into what specific demographic and descriptive variables may be associated with respondents concern for the suspension of environmental and food safety regulations.

Table 1 presents the results for level of concern about violations of environmental and food safety regulations during the COVID-19 pandemic. Chi Square tests of independence indicate that, on average, respondents were concerned about violations of environmental and food safety regulations for both surveys ( $p$ value $<0.001$ for all four tests). There was a slight increase in concern about environmental regulation violations from May to June ( $p$ value $=0.08$ ), and an even more pronounced increase in concerns about food safety violations $(p$ value $<0.01$ ). The relatively greater increase in concern about food safety regulations from May to June is even more apparent when comparing concerns about environmental and food safety regulations within a particular survey. That is, while there was no significant difference between concerns about environmental and food safety regulation in May $(p$ value $=0.16)$, a difference was detected in June $(p$ value $=0.02)$.

Overall, we find that $80.95 \%$ of respondents believed that their own individual responses to the pandemic were appropriate while $13.81 \%$ believed that they themselves had overreacted, and $5.24 \%$ believed that they had under-reacted. In order to gain further insight into respondents' risk perceptions, we asked them to choose from a list the three issues that most concerned them and least concerned them during the ongoing pandemic.

Figure 1 shows responses to specific COVID-19-related risks and how consumers' prioritization of those risks changed between surveys. We find that respondents ranked "being 


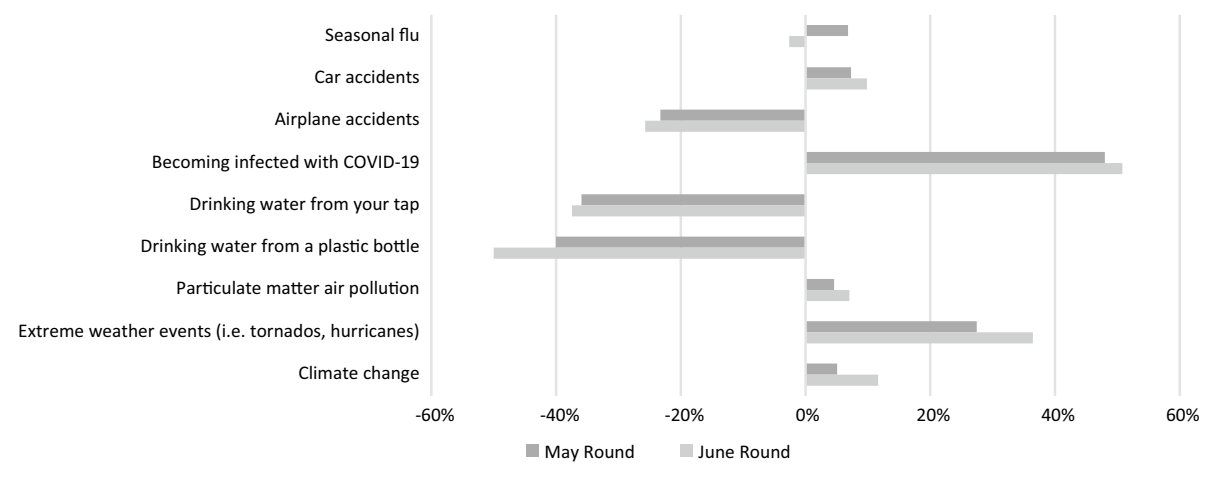

Fig. 2 Most and least stated general risk concerns between May and June 2020. Note: Bars from zero percent going left indicate least concern, whereas bars from zero going right indicate most concern

in close proximity to strangers" as most concerning and "being in close proximity to family members" as least concerning in both May and June. However, they were more concerned about being around strangers and less concerned about being around family in June than they were in May. Despite their concern about proximity to strangers, respondents were not very concerned about maintaining social distancing; they generally rated their concern about going to a public park as low with social distancing in place and only slightly greater when social distancing was not in place. Being indoors with others ranked second in terms of their most serious concerns in both May and June.

Figure 2 shows responses to broader types of risk, including transmitting and contracting COVID-19 and risks such as drinking water and severe weather events, to put their COVID-19 fears into context. In both survey months, contracting COVID-19 was the respondents' greatest concern, and the average degree of concern increased between surveys. Likewise, respondents were least concerned about drinking water from plastic bottles, and they became less concerned in June as more was known about the pandemic (their concerns about drinking tap water were similar). After COVID-19, respondents were most concerned about the risk posed by extreme weather events such as tornados and hurricanes, which are linked to climate change, and the degree of concern grew substantially between the May and June surveys. Respondents ranked seasonal flu as one of their greatest concerns in May and as one of their least concerns in June.

To explore these concerns further, we estimated an ordered probit model (Table 2) to examine the relationship between the ordinal variables of concern about violation of environmental practices and regulations (M1) and concern about violation of food safety regulations (M2) and independent demographic variables, such as age and education, as presented in Table 3. Because of the lack of previous empirical work on this topic, we identifed additional variables (V1-10) which impacted responses.

Our results show that sex and income are not significantly associated with an increase in respondents' concern about environmental and food safety violations. Respondents who reported to be of "other" race, where more concerned about food safety violations during the pandemic $(p=0.039)$ - we did not find any other statistically significant effect with respect to race. Older respondents were relatively more concerned than younger respondents about violations of environmental regulations $(p=0.041)$. This result was not expected since younger people are typically more concerned about the environment (Funk and Hefferon 2019). We also found that higher levels of education are associated with greater 
Table 2 Ordered probit model for environmental and food safety concerns

\begin{tabular}{|c|c|c|c|c|c|c|}
\hline \multirow[t]{2}{*}{ Dependent variable } & \multicolumn{3}{|c|}{$\begin{array}{l}\text { M1: } y=\text { environmental concern } \\
(n=2054)\end{array}$} & \multicolumn{3}{|c|}{$\begin{array}{l}\text { M2: } y=\text { food safety concern } \\
(n=2054)\end{array}$} \\
\hline & Coef. & SE & $p$ value & Coef. & SE & $p$ value \\
\hline Sex & -0.014 & 0.052 & 0.786 & 0.049 & 0.052 & 0.346 \\
\hline Age & 0.003 & 0.002 & 0.041 & 0.000 & 0.002 & 0.898 \\
\hline Income & 0.006 & 0.008 & 0.478 & -0.005 & 0.008 & 0.556 \\
\hline Education & 0.054 & 0.021 & 0.011 & 0.068 & 0.021 & 0.001 \\
\hline \multicolumn{7}{|l|}{ Race } \\
\hline 2 & 0.038 & 0.082 & 0.641 & 0.120 & 0.083 & 0.146 \\
\hline 3 & 0.024 & 0.293 & 0.935 & 0.290 & 0.288 & 0.314 \\
\hline 4 & -0.132 & 0.123 & 0.283 & 0.029 & 0.125 & 0.814 \\
\hline 5 & 0.001 & 0.343 & 0.998 & 0.093 & 0.336 & 0.783 \\
\hline 6 & -0.046 & 0.113 & 0.685 & 0.082 & 0.114 & 0.471 \\
\hline Other & 0.012 & 0.106 & 0.911 & 0.222 & 0.107 & 0.039 \\
\hline V1: Gov. opening too slowly & -0.025 & 0.020 & 0.207 & -0.034 & 0.020 & 0.092 \\
\hline V2: Gone without food & 0.194 & 0.068 & 0.005 & 0.212 & 0.069 & 0.002 \\
\hline V3: Trust in local gov. & 0.030 & 0.031 & 0.326 & 0.009 & 0.031 & 0.770 \\
\hline V4: Trust in state gov. & 0.039 & 0.028 & 0.167 & 0.030 & 0.028 & 0.280 \\
\hline V5: Trust in federal gov. & -0.039 & 0.022 & 0.080 & -0.004 & 0.022 & 0.843 \\
\hline V6: Following science advice & -0.091 & 0.042 & 0.030 & -0.175 & 0.042 & 0.000 \\
\hline V7: Passing COVID-19 to others & 0.210 & 0.022 & 0.000 & 0.174 & 0.022 & 0.000 \\
\hline V8: Others passing COVID-19 & 0.191 & 0.023 & 0.000 & 0.226 & 0.023 & 0.000 \\
\hline V9: COVID-19 conspiracy theory & 0.077 & 0.020 & 0.000 & 0.090 & 0.020 & 0.000 \\
\hline V10: Started a garden & 0.043 & 0.042 & 0.307 & -0.042 & 0.042 & 0.324 \\
\hline May survey & -0.049 & 0.047 & 0.300 & -0.110 & 0.048 & 0.021 \\
\hline Cut1 & 1.580 & 1.017 & & 1.273 & 1.023 & \\
\hline Cut2 & 2.197 & 1.017 & & 1.903 & 1.023 & \\
\hline Cut3 & 3.089 & 1.017 & & 2.810 & 1.023 & \\
\hline Cut4 & 4.125 & 1.018 & & 3.924 & 1.025 & \\
\hline
\end{tabular}

For the Race variable above, 2=Black or African American, 3=American Indian or Alaska Native, $4=$ Asian, $5=$ Native Hawaiian or Pacific Islander, 6=Spanish, Hispanic, or Latino, $7=$ Other

concern about environmental $(p=0.011)$ and food safety $(p=0.001)$ violations during the pandemic. Age did not play a significant role for food safety concerns.

We find that respondents' agreement with the statement "the government is reopening the economy too slowly" [V1] was not significantly associated with their concern about the environment; it was, however, marginally significantly associated with their concern for food safety violations $(p=0.092)$.

We did find a strong relationship between food security and environmental concern. Respondents who reported having "gone without food because of the COVID-19 pandemic" [V2] were significantly more likely to be concerned about environmental violations $(p=0.005)$ and food safety $(p=0.002)$ than respondents who had not gone without food.

In terms of state and local government versus the federal government [V3-V5], respondents who viewed the federal government as more trustworthy were less likely $(p=0.080)$ to be concerned about environmental violations, a relationship that did not exist for trust in 
Table 3 Respondent characteristics for both surveys

\begin{tabular}{|c|c|c|}
\hline Question & May & June \\
\hline Age & $\begin{array}{l}\text { Mean }=44.79 \\
S D=17.07\end{array}$ & $\begin{array}{l}\text { Mean }=45.39 \\
S D=17.53\end{array}$ \\
\hline \multicolumn{3}{|l|}{ Sex } \\
\hline Male & $48.95 \%$ & $49.00 \%$ \\
\hline Female & $51.05 \%$ & $51.00 \%$ \\
\hline Income & $\begin{array}{l}\text { Mean }=\$ 71,985 \\
S D=\$ 1787\end{array}$ & $\begin{array}{c}\text { Mean }=\$ 69,517 \\
S D=\$ 1694\end{array}$ \\
\hline Less than $\$ 10,000$ & $7.14 \%$ & $6.76 \%$ \\
\hline$\$ 10,000$ to $\$ 19,999$ & $8.19 \%$ & $8.67 \%$ \\
\hline$\$ 20,000$ to $\$ 29,999$ & $11.52 \%$ & $9.52 \%$ \\
\hline$\$ 30,000$ to $\$ 39,999$ & $7.43 \%$ & $7.71 \%$ \\
\hline$\$ 40,000$ to $\$ 49,999$ & $5.71 \%$ & $7.33 \%$ \\
\hline$\$ 50,000$ to $\$ 59,999$ & $10.57 \%$ & $9.52 \%$ \\
\hline$\$ 60,000$ to $\$ 69,999$ & $6.29 \%$ & $7.90 \%$ \\
\hline$\$ 70,000$ to $\$ 79,999$ & $8.29 \%$ & $7.14 \%$ \\
\hline$\$ 80,000$ to $\$ 89,999$ & $3.52 \%$ & $3.81 \%$ \\
\hline$\$ 90,000$ to $\$ 99,999$ & $4.38 \%$ & $4.67 \%$ \\
\hline$\$ 100,000$ to $\$ 149,999$ & $16.48 \%$ & $13.4 \%$ \\
\hline$\$ 150,000$ or more & $10.48 \%$ & $13.52 \%$ \\
\hline \multicolumn{3}{|l|}{ Education } \\
\hline Less than high school degree & $3.24 \%$ & $2.67 \%$ \\
\hline High school graduate & $28.19 \%$ & $29.05 \%$ \\
\hline Some college but no degree & $30.57 \%$ & $30.29 \%$ \\
\hline Associate degree in college (2-year) & $9.71 \%$ & $7.81 \%$ \\
\hline Bachelor's degree in college (4-year) & $14.95 \%$ & $13.33 \%$ \\
\hline Graduate or Professional degree & $13.33 \%$ & $16.86 \%$ \\
\hline \multicolumn{3}{|l|}{ Race } \\
\hline White & $73.56 \%$ & $75.58 \%$ \\
\hline Black or African American & $12.63 \%$ & $8.53 \%$ \\
\hline American Indian or Alaska Native & $1.56 \%$ & $1.53 \%$ \\
\hline Asian & $3.84 \%$ & $4.76 \%$ \\
\hline Native Hawaiian or Pacific Islander & $0.91 \%$ & $0.90 \%$ \\
\hline Spanish, Hispanic, or Latino & $6.40 \%$ & $7.45 \%$ \\
\hline Other & $1.1 \%$ & $1.26 \%$ \\
\hline \multicolumn{3}{|l|}{ Political Party } \\
\hline Republican & $36.76 \%$ & $34.76 \%$ \\
\hline Democrat & $36.00 \%$ & $34.76 \%$ \\
\hline Independent & $21.14 \%$ & $23.43 \%$ \\
\hline Other & $1.05 \%$ & $1.33 \%$ \\
\hline No preference & $5.05 \%$ & $5.71 \%$ \\
\hline
\end{tabular}

local and state governments. No such relationship was found for respondents' food safety concerns. 
Moreover, the more respondents reported ignoring scientific advice about pandemic practices [V6] such as wearing face masks, the less concerned they were about environmental $(p=0.030)$ and food safety $(p<0.001)$ violations.

We also asked respondents about their concern about passing COVID-19 to others [V7] and others passing it to them [V8]. We find that greater concern about transmission of the virus is associated with greater concern about environmental $(p<0.001)$ and food safety $(p<0.001)$ violations.

Most respondents we asked, stated that they found it very believable that COVID-19 started in a Chinese laboratory (a conspiracy theory that spread on social media during the time of the pandemic, we are not aware of any scientific evidence of such claims) - more than half of the respondents stated that they found it somewhat or extremely believable. The probit model revealed that the more believable respondents find this the statement "COVID19 started in a Chinese lab" [V9] the more concerned they also were about the violation of environmental $(p<0.001)$ and food safety $(p<0.001)$ regulations and policies.

Twenty percent of our respondents stated that they started a garden because of COVID19-however using this variable in the probit model [V10] showed that this variable was not significantly associated with respondents environmental and food safety concerns. Lastly, we did not find significant differences between the responses in May and June survey responses with respect to respondents' concern about violations to environmental policy and regulations, but we did find a significant difference between the two surveys with respect to their concern for violations of food safety regulations-perhaps, this concern was driven by an increasing number of popular press articles reporting on COVID-19 outbreaks in meat processing plants in the U.S.

\section{Discussion}

According to a recent poll conducted by the Associated Press-NORC Center for Public Affairs Research (2020), COVID-19 mitigation measures passed by local and state governments in the United States have broad public support. Data from the May and June surveys suggest that most people believe their local and state governments have responded correctly to the pandemic ${ }^{1}$ (they do not express the same support for federal actions taken so far). The vast majority ( $81 \%$ ) of respondents also reported that they thought their own responses to the pandemic were appropriate.

These favorable perceptions of mitigation measures that rely on voluntary individual contributions to the public good are likely driven by their personal sense of urgency and risk. However, personal relationships and the effects of the pandemic on others could also make individuals more sensitive to other social and environmental issues that require urgent collective attention, such as the continuation and development of new regulations to protect the environment. Previous studies of individual experiences have shown that disasters affect public beliefs about environmental issues such as climate change and pollution (Albright and Crow 2019; Diamond 2005). Our survey results offer a unique insight into

\footnotetext{
1 Measured on a 1-5 Likert scale from extremely untrustworthy to extremely trustworthy, for trust in local government, we find a median of 4.0 and mean of 3.45 (standard deviation of 1.18); for trust in state government, we find a median of 4.0 and mean of 3.41 (standard deviation of 1.26). On the other hand, for trust in federal government, we find a median and mean of 3.00 (standard deviation of 1.38).
} 
participants perception during the ongoing pandemic, which certainly impacted and likely changed peoples' perceptions and experiences.

Our findings point to an emerging trend: people who are most directly affected by the pandemic, such as those who have gone without food and people who are most concerned about spreading and contracting the virus, are more likely than others to be concerned about protecting the environment. A potential explanation for this association is that their experiences with effects of the pandemic and their strong emotional reaction to it have made them more concerned about other major issues facing society, such as climate change and environmental health. Our analysis shows that about $18 \%$ of respondents had gone without food at some point due to the pandemic, making it a powerful existential threat and causing extreme stress. We likewise find that about $50 \%$ of respondents were somewhat or extremely concerned about passing COVID-19 to others and about $65 \%$ were somewhat or extremely concerned about contracting the disease. These fears undoubtedly provoke thoughts about mortality and cause substantial stress and emotional responses. Furthermore, having to rely on the government to protect them from the virus is likely to be associated with similar concerns about government protection from toxic environmental conditions.

The findings presented here are based on the first analysis of the Pandemic Food and Stigma Survey (PFSS), a nationwide representative sample of adults in the United States designed to identify how the pandemic is affecting residents' concerns. We specifically focused the analysis on regulatory concerns that arose and continue to arise due to the ongoing pandemic - this also means that things might (likely will) change in the future. The correlations we found, specifically those between environmental (or food safety) concerns and existential threats, such as the lack of food and other forms of extreme stress related to the pandemic, will require further supporting evidence before major conclusions can be drawn. Nonetheless, these results are meaningful and important as they contribute to a growing body of literature that suggest that personal experiences with disaster and the emotional response to them, makes people more receptive to other environmental and social issues. Thus, these results may provide guidance for researchers in formulating new research questions and designing studies to explore those questions, thereby supporting policymakers in their efforts to mitigate the environmental, societal, and economic impacts of the pandemic.

Acknowledgements We thank Daniel Bass for his valuable contributions to this research and his dedication to the Pandemic Food and Stigma Survey.

Funding Funding was provided by S Hallock Du Pont Endowment and USDA National Institute for Food and Agriulture (Grant No. \#2019-67023-29854).

\section{Appendix}

See Table 4. 
Table 4 Demographic quota compared to results

\begin{tabular}{llll}
\hline Demographic & Quota Goal (\%) & $\begin{array}{l}\text { Week 1 } \\
(\mathrm{N}=1050) \\
(\%)\end{array}$ & $\begin{array}{l}\text { Week 2 } \\
(\mathrm{N}=1050) \\
(\%)\end{array}$ \\
\hline Age & & & \\
$18-34$ & 30.0 & 30.5 & 30.5 \\
$35-54$ & 35.0 & 35.7 & 35.6 \\
$55+$ & 35.0 & 33.7 & 33.9 \\
Gender & & & \\
Female & 51.0 & 51.0 & 51.0 \\
Male & 49.0 & 49.0 & 49.0 \\
Income & & & \\
$\quad$ \$0-\$50 k & 40.0 & 40.0 & 40.0 \\
$\quad$ \$50 K-< $\$ 100 \mathrm{~K}$ & 33.0 & 33.0 & 33.0 \\
$\quad$ \$100 K + & 27.0 & 27.0 & 27.0 \\
Education & & & \\
$\quad$ No college & 62.0 & 62.0 & 62.0 \\
College degree & 38.0 & 38.0 & 38.0 \\
\hline
\end{tabular}

\section{References}

Albright EA, Crow D (2019) Beliefs about climate change in the aftermath of extreme flooding. Clim Change 155(1):1-17. https://doi.org/10.1007/s10584-019-02461-2

Associated Press-NORC Center for Public Affairs Research (2020) Many are wary of reopening. Accessed 7 June. www.apnorc.org/projects/Pages/Many-Are-Wary-of-Re-Opening-.aspx

Bondy M, Roth S, Sager L (2020) Crime is in the air: the contemporaneous relationship between air pollution and crime. J Assoc Environ Resour Econom 7(3):555-585

Burkhardt J, Bayham J, Wilson A, Carter E, Berman JD, O’Dell K, Ford B, Fischer EV, Pierce JR (2019) The effect of pollution on crime: evidence from data on particulate matter and ozone. J Environ Econ Manag 98:102267

Diamond J (2005) Collapse: how societies choose to fail or succeed. Penguin, Park Imperial

Environmental Protection Agency (EPA) (2020) COVID-19 implications for EPA's enforcement and compliance assurance program. Accessed 06 June. www.epa.gov/sites/production/files/2020-03/docum ents/oecamemooncovid19implications.pdf

Funk C, Hefferon M (2019) Pew Research Center, U.S. public views on climate change and energy. Accessed 07 June 2020. www.pewresearch.org/science/2019/11/25/u-s-public-views-on-climate-and-energy

Greenstone M, Fan G (2018) Air quality life index. Accessed 07 June 2020. https://dev-aqli-epic.pantheonsi te.io/wp-content/uploads/2018/11/12Facts.English.pdf

Lusk JL (2017) Consumer research with big data: applications from the food demand survey (FooDS). Am J Agr Econ 99(2):303-320

Messer KD, Schulze WD, Hackett KF, Cameron TA, McClelland GH (2006) Can stigma explain large property value losses? The psychology and economics of superfund. Environ Resour Econ 33(3):299-324

National Waste \& Recycling Association (NWRA) (2020) NWRA State Summary of Regulatory Flexibility. Accessed 12 June 2020. https://cdn.ymaws.com/wasterecycling.org/resource/resmgr/images/4.13.20_ State_Agency_Regulat.pdf

US Food and Drug Administration (FDA) (2020) Food safety and the coronavirus disease 2019 (COVID-19)

Wu X, Nethery RC, Sabath BM, Braun D, Dominici F (2020) Exposure to air pollution and COVID-19 mortality in the United States. medRxiv

Zentner E, Kecinski M, Letourneau A, Davidson D (2019) Ignoring Indigenous peoples-climate change, oil development, and Indigenous rights clash in the Arctic National Wildlife Refuge. Clim Change 155(4):533-544

Publisher's Note Springer Nature remains neutral with regard to jurisdictional claims in published maps and institutional affiliations. 